\title{
ENTRE FISSÕES E FUSÕES - A DINÂMICA SOCIAL MATSÉS E OS PROCESSOS DE TERRITORIALIZAÇÃO NA FRONTEIRA BRASIL-PERU
}

\author{
Rodrigo Oliveira Braga Reis ${ }^{1}$
}

\section{RESUMO}

O presente artigo trata da relação entre etnicidade e nacionalidade a partir da análise da situação do povo Matsés (Pano) que habita a zona limítrofe entre o Brasil e o Peru. Adotando a perspectiva de que as regiões fronteiriças configuram espaços que possibilitam observar as estratégias dos Estados e das populações locais de definição e redefinição territorial, buscamos abordar a etnicidade e a nacionalidade como expressões identitárias inter-relacionadas em um espaço sociocultural de fronteiras políticas entre países. A região estudada tem sido palco de diversas frentes econômicas, como a exploração da seringa e do caucho, posteriormente, a exploração madeireira e, mais recentemente, os projetos de concessão para exploração petrolífera no Peru e sua população é constituída de uma diversidade de povos indígenas, de comunidades ribeirinhas (pescadores, agricultores, seringueiros, extratores e coletores de modo geral) e por pessoas de outras regiões, como militares, pesquisadores e missionários. Neste cenário, os Matsés vêm estabelecendo diversas relações interétnicas ao longo do tempo, definindo e redefinindo sua identidade, construindo sua territorialidade e (re)formulando sua organização social e política. $\mathrm{O}$ quadro de relações estabelecidos entre os Matsés e as agências indigenistas governamentais e não governamentais, aliado às dinâmicas internas ao grupo, tem provocado tanto processos de sedentarização e fixação de comunidades quanto a mobilidade de grupos ou subgrupos na área do rio Javari e seus afluentes. Neste sentido, buscaremos discutir a configuração de novos padrões de territorialidade dos quais decorrem novas formas de organização social e política.

Palavras-chave: Matsés. Fronteiras. Identidades. Territorialidade.

${ }^{1}$ Mestre em Antropologia pela Universidade Federal de Pernambuco (2013). Docente do Curso de Bacharelado em Antropologia da Universidade Federal do Amazonas (UFAM). E-mail: roliveiraam@gmail.com. 


\begin{abstract}
This article research deals with the relationship between ethnicity and nationality through the analysis of the situation of the Matsés, an indigenous people of the Pano linguistic group that inhabit the border between Brazil and Peru. Adopting the perspective that border regions configure spaces that allows the observation of strategies of states and local communities to define and redefine territorial configurations the approach takes ethnicity and nationality as interrelated expressions of identity in socio-cultural political boundaries between countries. The region studied has been the scene of several economic fronts, including exploitation of rubber, then logging and, more recently, concession projects for oil exploration in Peru and its population is made up of a variety of indigenous peoples, riverine communities (fishermen, farmers, rubber tappers, extractors and collectors in general) and people from other regions, such as military, researchers and missionaries. In this scenario, the Matsés have established different relations over time, defining and redefining their identity, building their territoriality and (re)formulating its social and political organization. The frame of relationships established between Matsés and the governmental indigenous agencies, nongovernmental organizations, allied to the internal dynamics of the group, have led to sedentary communities and reducing the mobility of groups or sub-groups in the area of the river Javari and its tributaries. In this way, we aim to discuss the establishment of new patterns of territoriality, which develop new forms of social and political organization.
\end{abstract}

Keywords: Matsés. Borders. Identity. Territoriality. 


\section{Introdução}

O presente artigo apresenta algumas das informações e reflexões desenvolvidas na pesquisa que resultou em minha dissertação de mestrado que abordou a relação entre etnicidade e nacionalidade como expressões identitárias inter-relacionadas em um espaço sociocultural de fronteiras políticas entre países a partir de uma análise sobre a configuração histórica do povo Matsés. Também conhecido como Mayoruna, os Matsés são classificados no conjunto dos Pano Setentrionais e habitam comunidades situadas na zona limítrofe entre o Brasil e o Peru.

Por sua própria natureza convencional, as fronteiras se configuram como espaços que nos possibilitam observar diferentes estratégias dos Estados e das populações locais para definição e redefinição territorial, processos que ainda têm sido influenciados pela atuação de ONGs e de missões religiosas que, assim como os órgãos indigenistas do Estado, têm seu espaço de atuação demarcado junto aos povos indígenas assistidos.

A partir da análise das dinâmicas que confluíram para a constituição das comunidades Matsés nesta zona fronteiriça, busquei apreender a configuração histórica do povo Matsés partindo da consideração de que as identidades étnicas e nacionais que são acionadas - ou instrumentalizadas - em contextos específicos não são necessariamente contraditórias. A região estudada tem sido palco de diversas frentes econômicas, como a exploração da seringa e do caucho $^{2}$, posteriormente, a exploração madeireira e, mais recentemente, os projetos de concessão para exploração petrolífera no Peru. Sua população é constituída de uma diversidade de povos

\footnotetext{
${ }^{2}$ Ambas exploradas pela indústria da borracha, as árvores de seringueira (Hevea Brasiliensis) e caucho (Castilloa Ellastica) possuem diferenças botânicas e eram extraídas de maneira diferente, o que resultou em formas distintas de assentamento, sendo os caucheiros marcados pela itinerância, logo sem o estabelecimento de assentamentos definitivos. Alberto Chirif (2004) aponta para diferenças entre os processos de expansão da fronteira resultantes da produção da borracha e do caucho: "La diferencia entre estas especies [hévea e castilloa] no sólo atañe a cuestiones de carácter botánico, sino que también tiene importancia en los processos sociales vinculados a su aprovechamiento. En efecto, el caucho introdujo en su época una nueva modalidad de frontera, es decir, de expansión para la puesta en valor de los recursos. (...) la aparición del caucho creó un tipo de frontera extractiva cuya principal característica era la temporalidad de los asentamientos, ya que sólo duraban hasta que el recurso se agotase en una zona, para luego ser trasladados a outra (...)" (Chirif, 2004: 23).
} 
indígenas (a exemplo dos que habitam a Terra Indígena Vale do Javari no Brasil $^{3}$ ), de comunidades ribeirinhas (pescadores, agricultores, seringueiros, extratores e coletores de modo geral) e por pessoas de outras regiões vinculadas a instituições militares, de pesquisa e missionárias.

Neste cenário, os Matsés - assim como as demais etnias - vêm estabelecendo diversas relações interétnicas ao longo do tempo, definindo e redefinindo sua identidade, construindo sua territorialidade e (re)formulando sua organização social e política. Portanto, a configuração atual da territorialidade deste povo resulta de um complexo conjunto de relações estabelecidas, principalmente, a partir da segunda metade do século XX. Neste período, destacam-se a ação da Fundação Nacional do Índio (Funai) a partir de 1971 e, nos anos de 1990; o processo que possibilitou a criação da Terra Indígena Vale do Javari no Brasil (TIVJ). No território peruano, a presença missionária do Summer Institute of Linguistics (SIL) também se apresenta como um elemento explicativo dos processos de reconfiguração territorial Matsés a partir da década de 1960. Esta situação de contato, aliada às dinâmicas internas ao grupo, tem provocado tanto uma relativa sedentarização a partir da fixação de comunidades, quanto deslocamentos de grupos ou subgrupos - contribuindo, portanto, para a configuração de padrões de territorialidade que se constituíram situacionalmente.

Além de produzirem mudanças na ocupação territorial, o quadro de relações estabelecidas entre os Matsés e as agências indigenistas governamentais e não governamentais - também influenciam o processo de organização social e política do grupo. Tal como vem sendo tratado em um conjunto de trabalhos antropológicos que se debruçam sobre situações semelhantes, este processo pode ser analisado a partir da noção de territorialização (OLIVEIRA, 1998). Sob esta perspectiva, busquei apreender os processos de reorganização

${ }^{3}$ A Terra Indígena Vale do Javari (TIVJ) tem uma extensão de 8.527 .000 hectares e um perímetro de aproximadamente $2.068 \mathrm{~km}$. É a $3^{\mathrm{a}}$ maior área indígena do Brasil. Está situada na região do Alto Solimões, no sudoeste do estado do Amazonas, próxima à fronteira do Brasil com o Peru. Abrange áreas drenadas pelos rios Javari, Curuçá, Ituí, Itacoaí e Quixito, além dos altos cursos dos rios Jutaí e Jandiatuba, compreendendo terras dos municípios brasileiros de Atalaia do Norte, Benjamin Constant, São Paulo de Olivença e Jutaí. Nesta Terra Indígena vivem cerca de 5480 indígenas (Brasil, 2013) das etnias: Kanamari, Korubo, Kulina-Pano, Marubo, Matis, Matsés (Mayoruna), além de grupos isolados/autônomos localizados no Alto Jutaí, no Jandiatuba e no Quixito. 
social, o estabelecimento de novas identificações e a criação de mecanismos políticos especializados como decorrentes da atribuição de um território enquanto unidade político-administrativa do Estado.

Não obstante a importância da noção de territorialização para apreensão deste processo, abordaremos as dinâmicas que vêm se delineando no sentido da construção de uma identidade Matsés transfronteiriça no sentido de apreender como uma territorialidade e uma identidade que não se restringe aos processos de territorialização empreendidos pelos Estados Nacionais estão sendo circunstancialmente acionadas diante da possibilidade de exploração petrolífera nos territórios indígenas.

Após mais de uma década de homologação da TIVJ, o cenário político do movimento indígena do Vale do Javari tem se transformado. De modo geral, o Conselho Indígena do Vale do Javari (CIVAJA) criado no momento da mobilização em torno da demarcação da TI foi substituído por uma nova organização no ano de 2008 - a União dos Povos Indígenas do Vale do Javari (UNIVAJA) - e observa-se o surgimento de associações de abrangência mais restrita, delimitadas pelo pertencimento étnico e/ou pela localização da aldeia.

Nesse contexto, os Matsés também têm passado por estas transformações na sua organização política. Observa-se uma reorganização do grupo no sentido de construir formas organizativas que se articulam a partir de duas dimensões: a localidade e a que decorre das relações entre os povos indígenas do Vale do Javari e os Estados Nacionais. Recentemente, tem-se observado ainda uma tendência para a construção de uma unidade política entre as organizações indígenas brasileiras e peruanas que tem sido gestada no âmbito de eventos binacionais - a exemplo das quatro edições da Reunião Binacional Matsés Brasil-Peru e do I Jogos Bi-Nacionais dos Matsés - estabelecendo uma terceira dimensão de análise. A partir dos documentos elaborados nestas reuniões e dos relatos ouvidos durante o trabalho de campo realizado entre abril e junho de 2012, sabe-se que os eventos binacionais têm buscado fortalecer a unidade política entre os Matsés - tendo como uma das principais pautas, a concessão para exploração petrolífera em terras indígenas no Peru.

Em suma, a pesquisa retomada no presente texto teve o objetivo de estudar a noção de territorialidade entre os Matsés e sua relação com as 
identificações étnicas e nacionais a partir da reconstrução dos padrões de ocupação territorial acionados pelos Matsés frente à atuação de agentes estatais, ao desenvolvimento de projetos econômicos e ao contato com grupos missionários na região fronteiriça Brasil-Peru, considerando-se ainda o mapeamento de conflitos existentes entre a territorialidade Matsés e os territórios nacionais de Brasil e Peru e a identificação e análise das transformações vivenciadas por este povo em termos de sua organização política e social.

Além desta Introdução, o presente artigo está dividido em três seções e as Considerações Finais. A primeira parte reúne algumas observações sobre a base conceitual que nortearam a pesquisa, em seguida, busco reconstruir - de forma bastante sintética - os eventos relativos à configuração atual da distribuição das aldeias Matsés na região fronteiriça a partir da análise de entrevistas, das conversas realizadas durante o trabalho de campo, de etnografias e de documentos. Assim, a segunda e a terceira parte do texto são organizadas de forma a destacar três aspectos: a presença missionária no Peru através da atuação do SIL; o quadro de relações mantido com a Funai a partir de 1971 e a demarcação da TIVJ; e as frentes de expansão econômica na região.

\section{Fronteiras e Territorialidades Indígenas e Estatais}

A produção acadêmica sobre a construção de territórios indígenas, concebidos tanto como o resultado de territorialidades nativas quanto de processos de territorialização, é vasta e profícua ${ }^{4}$. Grupos étnicos, identidade étnica, etnicidades e nacionalismos; fronteiras, limites, boundaries, sociedades transfronteiriças; ou ainda, territórios, territorialidades específicas e territorialização são exemplos do conjunto de categorias, noções e conceitos elaborados para apreensão de processos que envolvem grupos e regiões distintas.

Os estudos sobre fronteiras - geográficas, simbólicas, étnicas,

\footnotetext{
${ }^{4}$ Vários autores buscam compreender as dinâmicas de conformação territorial em que os mais variados grupos - urbanos, rurais, ou étnicos - estão inseridos. De tais estudos decorrem o desenvolvimento de noções e categorias analíticas como: territorialização (OLIVEIRA, 1998) e territorialidades específicas (ALMEIDA, 2006). Para a compreensão da constituição de territórios e de Terras Indígenas, cabe ainda mencionar: MALDI, 1998; LITTLE, 2002; OLIVEIRA, 2002; GALLOIS, 2004; KENT, 2011; e outros.
} 
regionais, nacionais, etc. - compõem um amplo rol de escritos no campo da Antropologia, da História, da Ciência Política e outros ramos de conhecimento, assim como, nos documentos diplomáticos e militares ${ }^{5}$.

A construção social do espaço também é um tema profícuo nas discussões antropológicas. Diversos pesquisadores buscam compreender as dinâmicas de conformação territorial em que os mais variados grupos - urbanos, rurais ou étnicos - estão inseridos. Daí decorre o desenvolvimento de noções e categorias analíticas como: territorialização (OLIVEIRA, 1998) e territorialidades específicas (ALMEIDA, 2006).

No que tange à produção etnológica sobre a Amazônia, há uma vasta produção sobre o grupo linguístico Pano com a qual buscamos estabelecer um diálogo no desenvolvimento desta pesquisa. Pela proximidade e pela importância de seus estudos no conjunto da etnologia Pano, destacamos os trabalhos de Kenneth Kensinger - como o livro How real people ought to live: the Cashinahua of eastern Peru (1995) -, uma diversidade de textos publicados em Working Papers on South American Indians e em Tipití: Journal of the Society for the Anthropology of Lowland South America, além da produção de Philippe Erikson (1992, 1993, 1996 e outros).

\subsection{Limites, Fronteiras e Zonas Fronteiriças}

É possível encontrar diversas definições e usos para o termo "fronteira" e seus correlatos, como "limites" e "zona fronteiriça". Um primeiro uso comum destes termos está diretamente relacionado ao território dos Estados Nacionais, sendo, portanto, facilmente encontrado em documentos diplomáticos e militares, assim como em trabalhos - não somente destes, mas, principalmente - de historiadores e geógrafos. Tanto nos documentos oficiais, quanto nos estudos, não há uma definição homogênea e podemos encontrar o emprego de "limites" e "fronteiras" sem uma clara distinção entre estes.

\footnotetext{
${ }^{5}$ A exemplo disto, Marcia Anita Sprandel - em Breve Genealogia sobre os estudos de fronteiras \& limites no Brasil (2005) - nos apresenta uma relação de mais de 40 escritos de natureza teórica, didática-descritiva e provenientes de documentos oficiais que foram produzidos no período republicano.
} 
A definição de Hannerz (1997, p.15) para limite: "uma linha clara de demarcação, em relação a qual uma coisa ou está dentro ou está fora", nos parece apropriada para tratar das áreas que compreendem os distintos territórios nacionais. Tal linha de demarcação pode existir apenas como um segmento de coordenadas em um mapa, ou pode ser estabelecida fisicamente - como as margens do Rio Javari que servem de limites para os territórios do Brasil e do Peru.

Em seu trabalho de revisão sobre a antropologia da fronteira entre o México e os Estados Unidos, Alvarez Jr. (1995) empreende uma distinção das definições e usos dos termos frontier, borders, borderlands e boundary. Neste trabalho, borders e boundaries se aproximam do significado atribuído por Hannerz (1997) a "limite", uma vez que, segundo o autor, "Borders are traditionally defined as international boundaries between nation- states" (ALVAREZ JR.,1995, p.449).

Outro pesquisador do tema, Anthony P. Cohen - em Culture, identity and the concept of boundary (1994) -, também apresenta definições conceituais para estes termos, mas, diferentemente de Alvarez Jr. (1995), Cohen (1994) distingue border e boundary. Ao primeiro termo, o autor atribui aspectos físicos e factuais e o aproxima do termo frontier, pois ambos possuem aspectos de finitude e delimitação: "Border and frontier have the quality of finity, definity, about them. When they are crossed, one has definitely moved from the Cerdagne to Cerdanya. That is undeniable, for my passport stamp tells me so" (Ibid., p.56). O segundo termo "boundary”, por sua vez, é situado no campo da consciência, da percepção e da representação.

O antropólogo Jean-Pierre Chaumeil em um dos seus trabalhos sobre a região de fronteiras entre Brasil, Colômbia e Peru, afirma que o conceito de fronteira abrange realidades diferentes em função de sua dupla natureza: ser uma linha de separação e o lugar de se fazer contato (CHAUMEIL, 2000, pp.55-56). Atendo-nos ao primeiro caso, apreendemos da definição de Chaumeil que, enquanto ligne de séparation, este conceito se refere a uma demarcação geopolítica precisa que separa dois ou mais Estados. Trata-se de uma convenção resguardada pelo direito internacional através da qual se garante os limites de um território sobre o qual se exerce a soberania de um Estado (Ibid., p.56). Por outro lado, enquanto lieu de mise en contact, a fronteira entre Estados ou regiões se constituiria, sobretudo, em um 
espaço difuso, uma área sociopolítica ou cultural particular, resultante da interação das populações que a habitam e a transformam em um espaço contínuo (Ibid., p.56).

Em consonância com estes autores, adotamos a distinção entre "limites" e "fronteiras" no sentido em que tomamos o primeiro termo para nos referir à linha de demarcação/separação entre os Estados Nacionais, considerando-o, portanto, no seu aspecto de delimitador geopolítico; enquanto o segundo é utilizado para se referir a outros significados e usos.

Seguindo o diálogo com os autores acima, podemos retomar a discussão de Hannerz (1997) e a composição do "pequeno conjunto de metáforas geográficas" (p.20). Para este autor, ainda que "limite" pareça "combinar com 'fronteira' e 'zona fronteiriça", esses últimos termos "não implicam linhas nítidas e sim regiões, nas quais uma coisa gradualmente se transforma em outra, onde há indistinção, ambiguidade e incerteza" (Ibid., p.20).

Sob esta perspectiva, tomamos a fronteira enquanto região e não como linha. Para Alvarez Jr. (1995), os limites (boundaries) separam formações sociais, povos e regiões. De outra parte, o mesmo autor utiliza o termo borderlands (zona fronteiriça) para designar uma região que abriga um conjunto de práticas definidas e determinadas por estes limites, região esta que é caracterizada por conflitos e contradições tanto materiais quanto ideológicas.

Compreende-se, desta forma, as fronteiras - ou melhor, as regiões/zonas fronteiriças - como espaços de encontro e interação (CHAUMEIL, 2000; ZÁRATE BOTÍA, 2008; ALBUQUERQUE, 2005). Encontros marcados por conflitos e contradições materiais, culturais e ideológicas. É, portanto, um espaço de negociações de territórios e de territorialidades, e de construções identitárias envolvendo diversas populações locais com outras sociedades nacionais e Estados (ZÁRATE BOTÍA, 2008).

Há ainda outra utilização frequente do termo "fronteira" geralmente associada a processos de colonização e/ou de expansão econômica: "frente de expansão ou fronteira agrícola/econômica", ou ainda, "fronteira pioneira". No Brasil, tal concepção sobre fronteira emerge especialmente na década de 1970 a partir de estudos que apontavam as 
contradições e os conflitos decorrentes das frentes de expansão econômica empreendidas durante o regime militar, sobretudo na região amazônica. Neste quadro podemos destacar o trabalho de pesquisadores como Octavio Velho (1972; 1976), Roberto Cardoso de Oliveira (1976), Darcy Ribeiro (1977) e José de Souza Martins ([1997] 2009), nos quais são desenvolvidos conceitos e noções que contribuíram para a compreensão de conflitos sociais, étnicos, nacionais e civilizacionais (ALBUQUERQUE, 2005).

\section{A dinâmica social Matsés e os processos de territorialização na fronteira}

A partir do século XIX, a consolidação dos Estados Nacionais latinoamericanos fundamentou-se em relações sociais, políticas e econômicas desenvolvidas no período colonial. $\mathrm{O}$ processo de estabelecimento dos limites geopolíticos através da delimitação territorial, as ações que visavam a garantia da soberania nacional e a nacionalização (LÓPEZ GARCÉS, 2000) dos povos indígenas representaram - para os ameríndios que sobreviveram à violência da colonização europeia - a continuidade de violentas práticas jurídicas, políticas e ideológicas. A este respeito, a literatura informa que a região de fronteiras entre Brasil, Colômbia e Peru se consolidou sobre o território ancestral de diversos povos, dentre eles os Tikuna e os Matsés 6 .

As referências etnográficas acerca do grupo Mayoruna (MONTAGNER \& MELATTI, 1975; ROMANOFF 1984; COUTINHO JR., 1993; ERIKSON, 1992; KOVASNA, 2009; MATOS, 2009; e outros) nos informam, por sua vez, que esta terminologia não corresponde a um povo, porém, a um conjunto de povos. Assim, Erikson (1992) utiliza este termo para designar um dos sete "subconjuntos principais no seio do bloco pano" (ERIKSON, 1992, p. 240), o qual compreenderia, além dos Matsés: “os Matis, os Korubo, os Kulina-Pano, os Maya e vários outros grupos, todos falantes de dialetos mutuamente inteligíveis" (Ibid. p.242).

${ }^{6} \mathrm{~A}$ situação dos povos indígenas amazônicos nos processos de definição das fronteiras nacionais tem sido tema de diversas pesquisas, como: Chaumeil (1996); López Garcés (2000, 2005); Faulhaber (2005); Zárate Botía (2008); Pimenta (2009); e outros. 
Os trabalhos de Erikson $(1992 ; 1993 ; 1996)$ fazem referência a um conjunto de grupos locais distribuídos em ambos lados da fronteira peruano-brasileira e tradicionalmente agrupados através do nome genérico de "Mayoruna" (SANTOS \& BARCLAY, 1994). O "macroconjunto pano" é representado por este autor como uma "nebulosa compacta", pois, apesar de sua extrema atomização interna, os grupos humanos que o conformam apresentam uma notável unidade linguística, territorial e cultural (ERIKSON, 1993, p.45).

"Mayoruna", enquanto um dos conjuntos locais do "macro-conjunto pano", é composto por "grupos locais" subdivididos, por sua vez, em "assentamentos locais" - estes últimos corresponderiam às antigas malocas ou às atuais aldeias/comunidades. Deste modo, no contexto do macro-conjunto pano, os grupos locais seriam os portadores de uma identidade diferenciada que corresponderia a um grupo/unidade étnica (SANTOS \& BARCLAY, 1994, p.XXII).

Tendo sua origem provável na língua quechua (onde, mayu = rio; runa = gente), o termo foi empregado a partir do século XVII por colonizadores, missionários e viajantes para se referir a grupos que habitavam a região do baixo Ucayali, alto Solimões e Javari (ROMANOFF, 1984; ERIKSON, 1992; COUTINHO JR., 1993; MATOS, 2009). Coutinho Jr. (1993, p.7), afirma que com o tempo seu uso foi se tornando mais restrito até ser incorporado especificamente para dois grupos que continuam sendo chamados "Mayoruna' pela literatura etnológica, linguístico-missionária e indigenista". Os dois grupos ao qual este autor se refere são: os chamados "Mayoruna do Marajaí", habitantes do médio rio Solimões, próximo à cidade de Tefé (AM); e os denominados "Mayoruna" que se autodenominam Matsés (ROMANOFF, 1984; COUTINHO JR., 1993) e habitam a região de fronteira entre o Brasil e o Peru.

Considerando a autodenominação e o recorte geográfico da pesquisa realizada, utilizarei o termo Matsés, sem, contudo, desconsiderar dados e pesquisas históricas sobre os chamados Mayoruna, entendendo que estas informações propiciam um panorama mais amplo dos processos que levaram à atual organização e distribuição territorial dos Matsés.

Devemos ter em mente que para determinar a área em que vivem os Matsés deve-se considerar um contínuo processo de territorialização através do estabelecimento de comunidades, das roças utilizadas 
cotidianamente e antigas que podem ser reocupadas, das expedições de caça e pesca, do deslocamento de famílias para cidades brasileiras e peruanas, como Angamos (Peru), Palmeiras do Javari, Atalaia do Norte, Benjamin Constant e Tabatinga (Brasil). Portanto, uma intensa mobilidade de famílias entre as aldeias e as cidades, cujos dados populacionais se mostram mais profícuos se forem compreendidos enquanto dados que se referem a configurações sociais que se delinearam em determinadas situações históricas. Atualmente estimase que a população Matsés está distribuída em 14 aldeias nos rios Javari, Curuçá e Pardo, e em tributários como os igarapés Lobo e Lopes; a população Matsés no Brasil é estimada em 1912 pessoas (BRASIL, 2013). No Peru, a população aproximada é de 1.800 pessoas distribuídas em 17 comunidades nos rios Gálvez, Choba e Javari (FLECK, 2003; KOVASNA, 2009; MATOS, 2009; DIAS, 2012).

Considerando os limites do presente artigo, apresento a seguir dados e reflexões acerca do conjunto de relações estabelecidas pelos Matsés a partir da segunda metade do século XX, não abordando, portanto, o período colonial e o ciclo da borracha na região.

A partir da década de 1920 - época do fim do ciclo da borracha houve um aumento no contato entre Matsés e não índios. No entanto, a maioria dos relatos coletados por Romanoff (1984) mostram que apenas uma parte do grupo Matsés estaria em contato mais permanente, enquanto a outra parte optava pelo isolamento. De qualquer forma, os contatos estabelecidos sempre eram completamente desfeitos depois de algum tempo, mantendo-se, geralmente, somente pelo tempo suficiente para se obter uma pequena quantidade de ferramentas de aço.

Montagner (1980), ratificando o processo de despovoamento por parte dos não índios no Vale do Rio Javari, afirma que por volta de 1921 inicia-se a exploração de madeira nos rios da região. Soma-se o comércio de carne e pele de animais da floresta. Assim, os conflitos que aparecem nos relatos a partir da década de 1920 são marcados, de um lado, por uma resistência de caráter mais guerreira dos Matsés e, de outro, pelas expedições punitivas chamadas comumente de "correrias". Houve casos de contato violento após os períodos de evasão e contato intermitente, sobretudo, da década de 1930 até o fim da década de 1960 - período em que raptos e assaltos eram práticas consideradas comuns do tratamento dispensado pelos Matsés aos outsiders. 
Tais práticas favoreceram o aumento da população e garantiram o acesso às ferramentas necessárias para a agricultura, o que contribuiu para a sobrevivência dos Matsés como uma população autônoma. De acordo com Romanoff (1984), serviram de motivação para os ataques, o desejo de capturar as mulheres, a vingança por invasões de seu território, uma animosidade geral aos nacionais e a crença de que um determinado grupo atacou e matou os Matsés com magia (ibid., 40). Matos (2008; 2009) classifica as décadas compreendidas entre 1920 e 1960 como Período de Guerras e o descreve da seguinte forma:

Ao longo do século XX, até a década de 60, os Matsés empreenderam ataques a diferentes malocas ou grupos, muitas vezes falantes de línguas Pano. Nestes ataques, a prática era de exterminar os homens e raptar mulheres e crianças, que eram incorporadas às famílias dos guerreiros como esposas e filhos (MATOS, 2008, p.4).

Após o chamado Período de Guerras, ocorrem processos que levam a uma maior sedentarização entre os grupos Matsés, resultante, principalmente, da presença missionária do SIL no lado peruano e no Brasil pela ação da Funai. Este novo período, o do contato não violento, marca a fase atual da história Matsés (KOVASNA, 2009), caracterizada por mudanças na organização social dos Matsés e nas relações destes com os outros, como o estabelecimento de relações não belicosas com certos brancos (MATOS, 2008).

O estabelecimento de relações não violentas com o SIL aconteceu em 1969 após uma série de acontecimentos relatados pela própria organização em um boletim informativo disponibilizado virtualmente ${ }^{7}$ e também por Romanoff (1984) que desenvolveu sua pesquisa de campo cinco anos depois desta situação de contato e permaneceu entre os Matsés até 1976.

Assolados por doenças e com medo de ataques de estrangeiros, o grupo de Matsés que passou a viver em um conjunto de malocas construídas em torno da pista de pouso localizada às margens do rio Choba foi atraído, principalmente, pelo atendimento médico, o acesso a bens industrializados - como roupas, panelas, facões e machados - e pela proteção contra os ataques dos nacionais (ROMANOFF, 1984; MATOS, 2008; KOVASNA, 2009). Neste contexto, as principais

${ }^{7}$ Disponível em: www.sil.org/americas/peru/spa-pop/mcf_enfoque.pdf, acesso em 10.12.2012. 
atividades das missionárias se referiam à evangelização, à tradução da bíblia, ao estudo linguístico e à construção de várias obras, como a pista de pouso e alguns tanques de peixes (ROMANOFF, 1984, p. 51).

Pouco depois do contato estabelecido com o SIL, outro grupo se aproximou de um madeireiro peruano e estabeleceu relações com os peruanos da guarnição de Angamos localizada na confluência do alto rio Javari, ou Jaquirana, e o rio Galvez. Outros contatos também foram estabelecidos, dentre os quais, com um missionário católico, com madeireiros, com as equipes de exploração de petróleo no Brasil e Peru, e com agentes da Funai (ROMANOFF, 1984; MATLOCK, 1998, 2002; MATOS, 2008; KOVASNA, 2009). De acordo com Matlock (1998, p.34), o grupo de Matsés que fez contato com o SIL em 1969 era pequeno, no entanto, desde que o mesmo se estabilizou, outros grupos se dirigiram para o alto Choba, dentre os quais, famílias que habitavam quatro malocas no $\mathrm{Brasil}^{8}$.

Quanto à atuação da Funai, de acordo com Montagner (1980) “em 1969, já oficialmente se toma conhecimento da complexidade da área e se propõe através do sertanista Raimundo Pio de Carvalho Lima a criação de quatro Postos Indígenas na região abarcada pelos Rios Javari, Curuçá, Itacoaí e Ituí" (Ibid., p.296), porém os trabalhos da Funai só foram se concretizar em 1971, como resposta a propostas de construção de rodovias que atravessariam o Vale do Javari.

Neste contexto, a presença do SIL e da FUNAI desempenham um papel de destaque para a compreensão dos deslocamentos e das transformações nos padrões de assentamentos dos Matsés. Romanoff (1984) argumenta que o principal processo envolvendo os Matsés neste período foi a formação de assentamentos híbridos de ameríndios e burocratas - seja um grupo religioso ou uma agência do governo -, dos quais decorreram as seguintes mudanças: migrações para estabelecer relações com os não Matsés, sedentarização e aglomeração demográfica, fim das correrias e dos raptos de mulheres, e uma aquisição de quantidades sem precedentes de objetos manufaturados. Tais mudanças, na opinião de Romanoff, provocaram uma transformação cultural tão profunda entre os Matsés, quanto as ocorridas durante o boom da borracha (Ibid., p.5).

\footnotetext{
${ }^{8}$ Os deslocamentos para próximo das instalações do SIL são registrados por este antropólogo em um conjunto de mapas (cf. Matlock, 1998).
} 
Além da Funai e do SIL, os exércitos brasileiros e peruanos, e também a Petrobras, compõem o quadro das relações interétnicas dos Matsés na década de 1970. A Petrobras iniciou em 1970 a "prospecção de gás natural no Vale do Javari, retalhando com picadas o território ocupado pelos Mayoruna e realizando ali inúmeras detonações para a pesquisa sismográfica" (COUTINHO JR., 1998, p.34). A utilização de explosivos amedrontou os Matsés fazendo-os procurar contato pacífico com os brancos que trabalhavam a serviço desta empresa em uma base situada junto à pista de pouso denominada Bom Jesus (CEDI, 1981, p.27; COUTINHO JR., 1998, p.34). O exército brasileiro, dentre outras situações, foi envolvido nos conflitos entre os Matsés do igarapé Lobo que resultou em mortes de índios no ano de 1978. Durante estes conflitos, algumas famílias que habitavam este igarapé se refugiaram no pelotão de Palmeiras do Javari, sendo depois transportadas pela Funai para o baixo rio Javari formando a aldeia Lameirão (COUTINHO JR., 1998; MATOS, 2009; MATLOCK, 1998). Em decorrência de um posterior desmembramento da aldeia Lameirão, que foi excluída da área demarcada enquanto TI Vale do Javari, se formaram quatro aldeias Matsés no Brasil: Três José (sic) e Flores (no rio Javari), Fruta Pão (rio Curuçá) e Terrinha (rio Pardo).

Matlock (1998, p. 34) também atribui a estes conflitos a formação das aldeias San Juan e Santa Sofia no médio Jaquirana (Peru). Os habitantes de Santa Sofia nos anos seguintes se dividiram e seguiram direções distintas, há referências a um grupo que se estabeleceu, em 1979, pouco abaixo do local da antiga pista de pouso Bom Jesus constituindo uma aldeia com o mesmo nome e depois se mudou para as proximidades de Angamos (Peru), formando a aldeia Paujil. Outras famílias de Santa Sofia se mudaram para o rio Gálvez onde algumas se reuniram na aldeia Nuevo San Juan e outras fundaram a aldeia Nueva Chova (COUTINHO JR., 1998; MATLOCK, 1998).

Processos de nucleação-dispersão-nucleação são constantes nas informações a respeito da formação das aldeias Matsés. Além dos casos demonstrados acima, Matlock (1998) destaca a história da comunidade Buenas Lomas no Peru que, de acordo com este autor, apesar de aparecer como três aldeias sucessivas - uma comunidade de origem não identificada, Chësëmpi e Buenas Lomas -, devem ser tratadas como uma única aldeia que ao longo de 25 anos teria sofrido apenas mudanças de localização e algumas raras e pequenas dissensões. Ainda sobre Buenas Lomas, Matlock (1998, p.35, tradução 
nossa) afirma: "Nada de seu tamanho e longevidade era conhecido tradicionalmente, e sua existência deve ser creditada à influência das políticas governamentais peruanas e ao SIL que incentivaram a permanência de assentamento".

O caso de Buenas Lomas ilustra algumas modificações nos padrões de assentamento dos Matsés decorrentes da formação dos "assentamentos híbridos" (ROMANOFF, 1984), como: a tendência a uma maior concentração populacional por aldeia, o estabelecimento de aldeias nos cursos dos rios ao invés dos igarapés e, uma terceira mudança observada, a substituição das malocas por casas, construídas segundo o modelo regional, separadas por famílias conjugais.

Uma maior sedentarização experimentada pelos Matsés decorre de uma situação de contato mais intensiva marcada por uma maior exposição e influência dos padrões de vida nacionais, incluindo a construção de escolas e hospitais. Por outro lado, o esgotamento de áreas para caçar, as disputas internas, doenças e mortes se apresentam como elementos explicativos dos deslocamentos. Assim, o estabelecimento de aldeias próximas às missionárias ou em locais que facilitem o acesso a órgãos governamentais, como a Funai, não significou o fim da mobilidade dos Matsés.

De acordo com Matos (2009, p.54), entre as décadas de 1940 e 1960, a expansão da atividade madeireira, o comércio de carne e pele de animais da floresta para abastecer principalmente as cidades da Amazônia peruana, "coincide com a criação do pelotão de fronteira peruano Angamos (em 1942), e dos pelotões de fronteira brasileiros Estirão do Equador (em 1958) e Palmeiras do Javari (em 1965), nas margens do rio Javari". A presença de madeireiros, pescadores e caçadores - os "invasores" aos quais os indígenas se referem em várias situações - propicia novos conflitos na área habitada pelos Matsés. Conforme relatos e documentos desse período, no Brasil a situação é agravada pela "participação do exército peruano e brasileiro em correrias punitivas contra os Matsés, acompanhadas por civis que tiveram parentes mortos pelos índios" (Ibid.). No território peruano, a mais famosa destas ações foi a que culminou com o bombardeio da área ocupada pelos Matsés por aviões da força área peruana em 1964 (NASCIMENTO 2006b; MATOS, 2009; DIAS, 2012). 
No Brasil, a exploração madeireira prosseguiu mesmo após a instalação da Funai na região no início dos anos 1970. Em meados da década seguinte, esta agência governamental organizou um grupo de estudo "composto por alguns de seus funcionários, por um antropólogo que há vários anos realiza pesquisas acadêmicas na região e por agentes indigenistas locais" (CAVUSCENS \& NEVES, 1986, p.10) para atualizar as informações sobre a realidade local, tendo em vista a interdição oficial da área indígena. Assim, em 1985 foi realizado o levantamento etnográfico e fundiário do Vale do Javari que fornecia à Funai as informações para agilizar o processo de delimitação da área, cabendo-lhe ainda o reconhecimento de algumas áreas para verificar a ocupação de grupos isolados (Ibidem).

Neste mesmo ano, através da portaria do presidente da Funai de n.1849/E, de 08 de abril; a área brasileira do Vale do Javari foi reconhecida como a "Terra Indígena Vale do Javari" e interditada pelo governo brasileiro, determinando a imediata retirada das equipes de trabalho da Petrobras, assim como de todos os "invasores" que se encontravam na Terra Indígena (Ibidem). Nascimento (2006b) ressalta que apesar desta interdição, o governo brasileiro não adotou nenhuma política de proteção e fiscalização, e as atividades exploratórias continuaram. A exemplo, ele afirma que "Nesse mesmo ano cerca de 2.500 não-índios ocupavam a área indígena, conformando uma população maior do que a população indígena contatada, estimada em 1.747 indígenas" (Ibid., p.3).

Apesar da resistência do setor madeireiro, em 2001 a área foi homologada como TI Vale do Javari destinando, assim, a maior parte das terras da margem brasileira do rio Javari ao usufruto restrito dos povos indígenas e estabelecendo um maior controle sobre a exploração dos recursos naturais no início deste século. Situação diferente tem sido enfrentada pelos indígenas que habitam o território peruano, pois, de acordo com Nascimento (2006a; 2006b), nos últimos anos ressurgiram os interesses econômicos pelas riquezas de suas matas através de projetos de concessões florestais.

Às invasões madeireiras, acrescentam-se grandes projetos de infraestrutura, a intensificação do narcotráfico e, mais recentemente, a decisão do governo peruano de abrir concessões para a exploração de petróleo e gás, atingindo as regiões do Javari, do Ucayali e Madre de Dios. Conforme afirma Pimenta (2009, p.12), "No fundo, trata-se de 
embates em torno de políticas desenvolvimentistas para essa região de fronteira". A região torna-se, portanto, palco de contradições constitutivas dos processos de desenvolvimento desejados por Estados e grandes corporações versus coletivos locais, indígenas ou camponeses. Como nos lembra os autores de "Amazonía Peruana en 2021 ", projetos políticos para "acelerar el desarrollo" não são novidades na região, a exemplo ressaltam que a "Amazonía brasileña, que fue sucesivamente sometida al Programa 'Brasil en Acción' (1996-1999), al 'Avanza Brasil' (2000-2003) y, actualmente, al 'Programa de Aceleración del Crecimiento' (PAC)", (DOUROJEANNI, M., BARANDIARÁN, A., \& DOUROJEANNI, D., 2009, p.22).

A respeito da atual concessão de lotes para a exploração petrolífera no Peru, em 2008 decretos legislativos foram ditados excepcionalmente pelo presidente Alan García determinando o processo de implementação de um Tratado de Livre Comércio (TLC) entre Peru e Estados Unidos (STETSON, 2012). De acordo com manifestantes contrários à ação governamental, dentre os quais se destaca a AIDESEP $^{9}$, este conjunto de leis facilitaria a entrada de investimentos estrangeiros para a exploração dos recursos hidrocarbonetos da selva peruana desrespeitando os direitos territoriais de povos ancestrais da floresta.

Ao final deste ano, indígenas Matsés encaminharam ofício ao presidente peruano, Alan García Pérez, a respeito da sobreposição dos Lotes Petroleiros 135, 136, 137, 142 e 152, concedidos pelo governo a favor das empresas Pacific Stratus Energy S.A. e Sucursal Peru, Occidental Oil \& Gas Of. Peru Sucursal do Peru, localizados no território da Comunidad Nativa Matsés. Neste documento os indígenas reivindicavam o cancelamento das concessões dos lotes sobrepostos ao seu território. Em abril de 2009, uma série de protestos de indígenas da Amazônia peruana geraram confrontos violentos com a polícia deste país na cidade de Bágua e deram visibilidade internacional à situação ${ }^{10 .}$

\footnotetext{
${ }^{9}$ Asociación Interétnica de Desarrollo de la Selva Peruana (AIDESEP)

${ }^{10} \mathrm{Cf}$. dentre outras fontes: "Matsés pedem que cancelem concessão de lotes sobrepostos a seus territórios" (Disponível em: http://www.adital.com.br/Site/noticia_imp.asp?cod=36607\&lang=PT, acesso em 20.12.2008) e "Conflito entre índios e polícia teria matado 47 no Peru" (Disponível em:http://www.bbc.co.uk/portuguese/noticias/2009/06/090606_perusabadoebc.shtml, acesso em 07.06.2009).
} 
Apesar dos protestos de organizações indígenas aliadas às organizações não governamentais, tanto no nível local quanto internacionalmente, dois lotes se sobrepõem a territórios ocupados pelos Matsés e também por povos em situação de isolamento. O primeiro, o Lote 135, está situado em uma área que tem sido reivindicada como reserva para proteger os índios isolados, enquanto o Lote 137 se sobrepõe ao território da Comunidad Nativa Matsés. Estes dois lotes foram concedidos para exploração à empresa Pacific Rubiales $^{11}$ que, de acordo com boletins do Centro de Trabalho Indigenista $^{12}$ e de uma campanha lançada pela Survival International ${ }^{13}$, já deu início às atividades de prospecção de linhas sísmicas do lote 135.

\section{Madeira, Petróleo e a criação de Terras Indígenas: Transformações nas relações com os Chotac e entre os Matsés}

A exploração destes recursos naturais e outras ações econômicas na região estão ligadas aos chamados projetos de desenvolvimento que podem ser classificados como as atuais frentes de expansão da fronteira econômica na região. Entretanto, nesta seção apresentarei alguns dados registrados durante a estadia na aldeia Lobo e de documentos e boletins informativos a respeito das reuniões binacionais no intuito de construir uma apreensão das transformações nas relações entre os grupos Matsés dos dois países e entre estes e os chotac $^{14}$.

Como fio condutor desta reflexão, apresento a seguir um trecho de uma entrevista concedida pelo professor indígena da aldeia Lobo, Gonçalo Mayoruna $^{15}$ :

\footnotetext{
${ }^{11} \mathrm{Na}$ página desta empresa na internet há informações sobre a exploração nos lotes situados no território peruano. http://www.pacificrubiales.com/operations/peru/exploration/217-peruexploration.html acesso em 15.03.2013

${ }^{12} \mathrm{O}$ Centro de Trabalho Indigenista tem atuado junto às organizações indígenas da região e produzido uma série de boletins informativos e mapas. Dentre outros boletins, cf. http://www.trabalhoindigenista.org.br/noticia.php?id_noticia=142 acesso em 15.03.2013

${ }^{13}$ Campanha disponível no site: http://www.survival.es/indigenas/matses acesso em 15.03.2013.

${ }^{14}$ Categoria nativa que designa os não índios.

${ }^{15}$ Gonçalo Mayoruna foi um dos meus principais interlocutores durante a pesquisa de campo.
} 
tá... como eu... eu sou casado com Matsés do Peru. Antes... depois de demarcação, nós somos Matsés do Brasil. Era culpado os Peru... do Peru dos Matsés, né? ... Nós somos... Falavam assim... os Matsés não podem entrar no Brasil porque nós somos demarcados, protegidos do Brasil e eles têm também terra. Tem pra casa, tem pra... assim, nós somos daqui. [...] Os caciques, lideranças discutiram entre eles: os Matsés do Peru poderiam passar no Brasil, pescar, caçar. Eu tá vendo hoje. Pra mim esses Matsés do Peru e do Brasil tá tendo... assim... juntos. Como dizer... juntos... melhorar, pra defender. Reunir todos com eles, né? Pra lutar pelo de fora, lutar pela terra, pensar como nossa terra, pra discutir fora com eles. Eu principalmente, pra mim... minha família... até eu participei do reunião bi-nacional dos Matsés... hoje acho que não tem como era antes não. Porque nós vivemos, tem sobrinho, irmão... reunir juntos... eu percebi já... reunimos juntos, sentemos com eles, até agora não tem como discutir... (Gonçalo Mayoruna).

Um primeiro aspecto a ser destacado nesta fala é o estabelecimento de dois períodos na relação entre os "Matsés do Brasil" e os "Matsés do Peru": um antes e um depois da demarcação da TI Vale do Javari. Conforme demonstrado anteriormente, a TI Vale do Javari foi homologada no ano de 2001, enquanto a Comunidad Nativa Matsés foi criada em 1993. Através da afirmação “depois de demarcação, nós somos Matsés do Brasil”, Gonçalo aponta para o estabelecimento de uma identificação nacional provocada por um processo de territorialização, isto é, a demarcação e homologação da TI Vale do Javari. É através deste processo que se estabelece a diferenciação entre os Matsés do Brasil e do Peru, formando dois coletivos de aldeias separados em dois territórios indígenas outorgados pelos respectivos Estados Nacionais.

A partir das conversas com outros Matsés, pude perceber que esta divisão foi acionada no período de demarcação e homologação da TIVJ, quando os Matsés que viviam no Brasil acusavam os Matsés que habitavam o território peruano de envolvimento com madeireiros e outros "invasores". Tal diferenciação também foi acionada por algumas lideranças no caso recente de reconhecimento e expedição de documentos civis brasileiros aos Matsés que formaram a aldeia José Meireles, ou, de modo contrário, sendo colocada em segundo plano 
por outras lideranças - como o cacique Antônio da aldeia Soles, que afirmou atender no posto de saúde instalado em sua aldeia os Matsés que venham de aldeias peruanas por considerar que todos são parentes.

No entanto, um segundo aspecto de sua fala merece ser analisado com maior detalhe. De acordo com Gonçalo, "hoje acho que não tem como era antes não. Porque nós vivemos, tem sobrinho, irmão... reunir juntos... eu percebi já... reunimos juntos, sentemos com eles, até agora não tem como discutir...". Trata-se, portanto, de um novo contexto em que a distinção entre Matsés brasileiros/Matsés peruanos - não obstante ainda seja acionada em algumas situações - é subvalorizada em função da construção de uma unidade política binacional, ou transfronteiriça, que vem sendo gestada nos eventos binacionais. Neste conjunto de eventos, além das reuniões, deve ser incluído os I Jogos Bi-Nacionais dos Matsés, pois, conforme afirmação de Gaúcho ${ }^{16}$ em uma entrevista concedida em Atalaia do Norte, a realização dos jogos tinha como objetivo o fortalecimento da unidade entre os Matsés dos dois países.

Acompanhei algumas conversas e reuniões que corroboram para a compreensão deste processo durante o período em que estive na aldeia Lobo. Em uma reunião ocorrida no dia 12 de junho de 2012, o cacique Mocaci tratou de alguns assuntos referentes à fronteira Brasil-Peru e reafirmou a unidade dos Matsés:

Antes da demarcação [da TIVJ] havia muitos invasores. Depois da demarcação teve conflito com madeireiros. Teve madeireiro peruano que roubou nossas terras, que tiravam madeira no Brasil! Agora, com o petróleo, eu também estou preocupado. Não vai ser só no Peru não. Se poluir lá, vai poluir aqui. Vamos reunir Brasil e Peru para lutar pela nossa terra! O rio é internacional, não vamos deixar entrar. Somos parentes e vamos nos unir para lutar. Antes teve discussão com os Matsés do Peru porque eles traziam os madeireiros para o Brasil. Agora não! Fomos em reunião no Puerto Alegre e vamos lutar juntos! Aqui no Jaquirana tem muitos lagos, no Peru não tem muitos. Então, não era madeira que eles queriam, eles queriam os peixes, os tracajás, tirar copaíba... Agora estou preocupado de acontecer a mesma coisa. Vamos nos unir! $\mathrm{Eu}$ sei que é um rio só, que se poluir vai afetar todo

\footnotetext{
${ }^{16}$ Liderança indígena Matsés, no período do trabalho de campo era presidente da recém-criada Associação dos Matsés do Alto Jaquirana.
} 
mundo. Aqui pelo rio não vão entrar! Se não escutarem, vai ter guerra! (Cacique Mocaci).

Ao todo foram realizadas quatro reuniões binacionais, sendo que a primeira ocorreu no ano de 2009 e a quarta foi realizada no período de 09 a 11 de março de 2013 na aldeia Lobo. Cabe registrar que estas reuniões têm início justamente após as medidas do ex-presidente do Peru, Alan García, em favor da exploração petrolífera neste país. Deste modo, os temas que têm mobilizado lideranças Matsés, com apoio de organizações indigenistas como o CTI, além do petróleo, se referem ao controle territorial, à saúde, ao manejo sustentável dos recursos naturais e à situação de "povos isolados"

De acordo com matéria veiculada no Jornal A Crítica de $17.03 .2013^{18}$, mais de 100 lideranças Matsés estiveram presentes na IV Reunião Binacional Matsés Brasil-Peru e "repudiaram as atividades da empresa petroleira canadense Pacific Stratus Energy S.A". Conforme demonstrei, a preocupação atual recai principalmente na área do Lote 135, que é ocupada por índios isolados e onde os Matsés peruanos reivindicam há vários anos que o local seja reconhecido como terra ancestral deles com o nome de Reserva Indígena Yavari, Tapiche, Yaquerana, Chobayacu e afluentes.

\section{Considerações Finais}

Embora a presença dos Matsés na região seja anterior à definição dos limites entre Brasil e Peru, o período que compreende o início da atuação da Funai e o processo de territorialização desencadeado pela

\footnotetext{
${ }^{17}$ Os índios isolados são definidos pelo Estatuto do Índio em seu $4^{\circ}$ artigo: "quando vivem em grupos desconhecidos ou de que se possuem poucos e vagos informes através de contatos eventuais com elementos da comunhão nacional" (BRASIL, 1973 apud ARISI, 2007, p.30). Sem me estender aqui no debate sobre as implicações desta classificação, corroboro com a afirmação de Octavio e Azanha (2009) de que o sentido jurídico do termo isolado não deve encobrir a realidade sociológica vivenciada pelos povos indígenas sem contatos regulares com as sociedades do seu entorno. Portanto, o termo "isolado" não significa que um povo assim designado jamais travou contato com qualquer sociedade (o que é mesmo absurdo dizer), ou que desconhece por completo a sociedade "branca".

${ }^{18}$ Matéria disponível no portal do Jornal A Crítica: Atividade petrolifera no Peru ameaça recursos naturais $e$ índios isolados do Amazonas (http://acritica.uol.com.br/amazonia/AmazoniaAmazonasManaus_0_883711667.html).
} 
criação da TI Vale do Javari aliado à luta contra a continuidade da atuação de madeireiras peruanas, introduziram uma noção de "fronteira" como limite territorial e diferença intraétnica manifesta através do acionamento da identificação nacional entre Matsés brasileiros/Matsés peruanos. A demarcação da Terra Indígena Vale do Javari, contou com a participação dos índios que acompanharam em campo os trabalhos dos técnicos da Funai.

A experiência da demarcação parece ter fomentado uma nova concepção do território, em que seus "limites" tornaram-se realidades mais concretas. Em diversas reuniões e assembleias do movimento indígena do Vale do Javari pude observar a utilização de um mapa da Terra Indígena, elaborado pelo PPTAL, que as lideranças se referiam tanto para a representação de sua maior conquista - a terra demarcada - quanto para indicar no mapa os locais em que ocorriam conflitos com invasores e as aldeias que careciam da assistência dos órgãos públicos.

O novo quadro de relações interétnicas instituído a partir da década de 1970 nos dois países causou transformações importantes no padrão de assentamento dos Matsés. O contato pacífico, com as missionárias ou com a Funai, desencadeou a formação do que Romanoff (1984) chamou de assentamentos híbridos, que somados aos processos de territorialização dos quais resultaram a criação dos respectivos territórios indígenas - a TI Vale do Javari e a Comunidad Nativa Matsés - instituíram a "fixidez da comunidade" em contraposição à "mobilidade de 'antigamente', quando as diferenciações entre os grupos locais não estavam atreladas a um território previamente definido, com limites físicos (MATOS, 2009, p.71).

No Brasil, a atuação da FUNAI e, posteriormente, a mobilização em torno da criação da Terra Indígena do Vale do Javari, possibilitou a criação de formas associativas entre povos antes considerados rivais elementos que contribuíram para o controle ou mesmo para a extinção de situações conflituosas envolvendo povos indígenas, a exemplo dos ataques empreendidos pelos Matsés a outros grupos Pano (COUTINHO Jr., 1998; Matos, 2009). Exemplo desta nova situação, a mobilização pela demarcação da Terra Indígena propiciou a fundação, em 1991, do Conselho Indígena do Vale do Javari (CIVAJA), formado por lideranças Marubo, Matsés, Kanamari e Kulina. 
Neste contexto emerge a criação de uma distinção entre "Mayoruna" e "Matsés". Conforme observei nos documentos elaborados entre a década de 1970 e o início deste século, o indigenismo oficial brasileiro adotou a classificação Mayoruna, desenvolvida no período colonial. No entanto, diferente da sua primeira formulação que se referia àqueles indígenas classificados pelos topos brancos e barbudos (COUTINHO Jr., 1993), portanto, sem "fronteiras" claras da definição do grupo, ao empregar esta classificação se instituía um grupo étnico com os limites estabelecidos pelo Estado brasileiro: os "Mayoruna do Vale do Javari".

Entendendo "grupo étnico" como "uma unidade com fronteiras bem delimitadas" que "possui cultura, 'raça' e língua próprias, diferentes das outras etnias” (REESINK, 1983, p.123) é possível apreender que tal classificação transforma um conjunto de assentamentos locais em uma etnia que deve ser considerada diferente de outros conjuntos próximos, linguística e culturalmente, como os Matis e os Marubo, no Brasil, e os Matsés do Peru. Afirmações como a feita por Gonçalo de que "os Matsés [do Peru] não podem entrar no Brasil porque nós somos demarcados, protegidos do Brasil e eles tem também terra" ou, a proferida por Mocaci: "antes teve discussão com os Matsés do Peru porque eles traziam os madeireiros para o Brasil" remetem a um passado, não tão distante, em que os Matsés - pelo menos na relação com os seus respectivos Estados Nacionais - estavam divididos em Mayoruna e Matsés.

No nível das relações entre os grupos locais, isto é, entre as aldeias Matsés, pude observar que relações de reciprocidade, como os casamentos, se mantêm apesar dos limites nacionais e da criação dos respectivos territórios indígenas. Enquanto que, no quadro das relações interétnicas, os Matsés precisam se adequar aos critérios de indianidade dos Estados Nacionais, que refletem nas formas de organização política e social adotadas a partir dos marcos legais de cada país.

Os Matsés do lado brasileiro da fronteira, com a criação da TI Vale do Javari e a sua organização indígena representativa, o CIVAJA, passaram a integrar a classificação "Povos Indígenas do Vale do Javari”, ou mesmo, como escutei diversas vezes, a de "os índios do Javari” em contraposição aos outros povos indígenas da região do Alto Solimões como os Tikuna ou os Kokama. Tal classificação se origina 
na peculiaridade do território indígena criado na bacia do rio Javari, apesar da nomenclatura "Terra Indígena", este território se assemelha muito mais à ideia de um "Parque Indígena" que reúne uma diversidade de povos em situações diferenciadas de contato com a sociedade envolvente, como os considerados "índios isolados".

O movimento indígena do Vale do Javari, após mais de uma década de homologação da referida Terra Indígena, vive um novo cenário político. O CIVAJA foi substituído por uma nova organização - a União dos Povos Indígenas do Vale do Javari (UNIVAJA) - e observa-se o surgimento de associações de abrangência mais restrita, delimitadas pelo pertencimento étnico e/ou pela localização da aldeia. As duas associações Matsés existentes no Brasil - a Organização Geral dos Mayoruna e a Associação dos Matsés do Alto Jaquirana - se consideradas no âmbito do movimento indígena brasileiro, parecem resultar deste processo e, conforme alegado pelos seus coordenadores - Vitor Mayoruna e Gaúcho, respectivamente - favoreceriam os Matsés do Brasil à medida que se constituem como uma via de reivindicação direta e de acesso aos benefícios do Estado brasileiro. Não obstante, essas duas associações indígenas têm desempenhado um papel decisivo na construção da unidade política entre as organizações indígenas brasileiras e peruanas - esta gestada no âmbito dos eventos binacionais.

Do conjunto de eventos binacionais realizados nos últimos quatro anos, destaquei as quatro edições das reuniões binacionais e a realização do I Jogos binacionais. As duas associações dos Matsés do Brasil têm participações diferentes nestes eventos, a OGM junto com a jefatura da Comunidad Nativa Matsés e em parceria com ONGs, como o CTI, é responsável pela realização das reuniões binacionais. Por outro lado, a AMAJA foi a responsável pela realização dos jogos. Não obstante a atuação dessas associações nos referidos eventos serem diferentes, ambas têm atuado no fortalecimento da unidade transfronteiriça dos Matsés. Ainda que as reuniões binacionais tenham um caráter político explícito e propiciem uma maior visibilidade às reivindicações, considero que a realização dos jogos também desempenha um papel importante neste processo.

Ações governamentais como a concessão para a exploração petrolífera no Peru, resultam de duas dinâmicas socioeconômicas que caracterizam os fluxos recentes do espaço amazônico: de um lado, as 
dinâmicas colonialistas internas apontam para a expansão das fronteiras econômicas das sociedades nacionais em direção aos limites da floresta amazônica - tidos como de baixa atividade econômica e com elevado potencial energético, mineral, madeireiro e petrolífero. De outro lado, a expansão do sistema mundial através de movimentos de transposição para os territórios periféricos do sistema capitalista de obras de infraestrutura de grande escala, visam explorar recursos naturais e, assim, produzir espaços produtivos dentro do jogo de comércio internacional (Medeiros, 2009, p.20). Em suma, os projetos de desenvolvimento em voga nos países amazônicos correspondem à atualidade das frentes de expansão e, não obstante as transformações que possam ter ocorrido na ideologia étnica (REESINK, 1983) nas últimas décadas, reacendem concepções como a do "vazio demográfico" e de que os povos indígenas são entraves ao "desenvolvimento nacional".

Como demonstrado anteriormente, um dos sentidos atribuídos à "fronteira" é o de "frente de expansão econômica", atualmente representada pela frente de exploração petroleira que sucedeu outras frentes econômicas e se articula a projetos desenvolvimentistas fundados em grandes obras de infraestrutura e na exploração de outros recursos naturais. A "fronteira" como "frente de expansão" é relevante para a análise dos outros dois sentidos que lhe são atribuídos: o geopolítico, ou seja, o dos "limites" internacionais; e o das fronteiras sociais e culturais expressos em diferenças intraétnicas (LÓPEZ GARCÉS, 2000; PIMENTA, 2012. A articulação analítica destes três sentidos corrobora a compreensão de que "o contexto político e econômico é fundamental para o entendimento nativo do limite internacional e da produção social das diferenças" em regiões de fronteiras internacionais (PIMENTA, 2012, p.93).

Da atualidade da "frente de expansão econômica" na região resultam novos conflitos entre as práticas territoriais estatais e indígenas. A unidade transfronteiriça dos Matsés emerge deste contexto como uma nova forma de organização política para forçar os Estados Nacionais brasileiros e peruanos a solucionar o conflito. O reconhecimento da emergência desta "unidade transfronteiriça" não pretende negar situações em que a divisão peruanos/brasileiros se conforma como mais uma possibilidade de criação de "fronteiras" intraétnicas, em que os Matsés instrumentalizem uma identidade nacional. Não obstante, há de se ter presente que tal unidade é fundamentada em relações de 
vizinhança e de reciprocidade entre assentamentos locais que compartilham uma unidade linguística, territorial e cultural que antecedem à instituição dos limites nacionais e da criação dos territórios indígenas.

Cabe observar também que esta unidade se constitui sem a manifestação pelo interesse de unificação territorial, ou seja, cada grupo permanece habitando territórios que são administrados por diferentes governos nacionais e não tem se mencionado a possibilidade de re-demarcação de um território contínuo que unifique as terras do grupo através de um acordo entre os governos do Brasil e do Peru diferentemente do que afirmam constantemente os militares brasileiros de que as Terras Indígenas situadas nas zonas de fronteira são uma ameaça à soberania nacional e atendem aos interesses de internacionalização da Amazônia conduzidos por ONG's internacionais. 


\section{Referências}

ALBUQUERQUE, J. L. C. Fronteiras em movimento e identidades nacionais: A imigração brasileira no Paraguai. Tese de Doutorado, Universidade Federal do Ceará, 2005.

ALMEIDA, A. W. B. Terras de Quilombo, Terras Indígenas, "Babaçuais Livres", "Castanhais do Povo", Faxinais e Fundos de Pasto: Terras Tradicionalmente Ocupadas. Manaus: PPGSCA-UFAM, 2006.

ALVAREZ JR., R. R. "The Mexican-US Border: The Making of an Anthropology of Borderlands". Annual Review of Anthropology, 24: 447-470, 1995.

ARISI, B. Matis e Korubo: Contato e Índios Isolados. Relações entre povos no Vale do Javari, Amazônia. Dissertação de Mestrado. UFSC, 2007.

BRASIL. Ministério da Saúde. Secretaria Especial de Saúde Indígena. Dados Populacionais de 2013 das Etnias cadastradas no SIASI por Distrito Sanitário Especial Indígena - DSEI. http://dw.saude.gov.br/gsid/servlet/mstrWeb. Acesso em 25 maio 2015.

CARDOSO DE OLIVEIRA, R. Identidade, Etnia e Estrutura Social. São Paulo: Livraria Pioneira Editora, 1976.

CAVUSCENS, S; NEVES, L. J. Povos Indígenas do Vale do Javari. Manaus: Campanha Javari. CIMI, OPAN. 1986.

CEDI (Centro Ecumênico de Documentação e Informação). Povos Indígenas no Brasil. São Paulo, 1981, volume 5 (Javari).

CHAUMEIL, J. P. "Par delà trois frontières. L'espace central du trapèze amazonien”. En Autrepart (14), 2000, pp. 53-70.

CHIRIF, A. "Época del caucho y barbarie" (Introdução à republicação do livro El Proceso del Putumayo y sus secretos inauditos publicado, de autoria do juiz Carlos Valcárcel em 1915). Iquitos, Monumenta Amazónica, CETA-IWGIA, 2004. 
COHEN, A. P. Culture, identity and the concept of boundary. Revista de antropología social, núm.3. Editorial Complutense, Madrid, 1994.

COUTINHO Jr., W. Brancos e Barbudos. Dissertação de Mestrado. Universidade de Brasília, 1993.

Relatório de Identificação e Delimitação da Terra Indígena

Vale do Javari. Brasília: FUNAI, 1998.

DIAS, R. L. MATSES NEBI ("Sou Matses/Sou Gente!"): Um estudo da identidade Matses como auto-designação étnica e autoafirmação de sua humanidade na natureza. UFAM, Monografia de Bacharelado, 2012.

DOUROJEANNI, M., BARANDIARÁN, A., \& DOUROJEANNI, D. Amazonía Peruana en 2021: Explotación de recursos naturales e infraestructuras: ¿Qué está pasando? ¿Qué es lo que significan para el futuro?. Pro Naturaleza - Fundación Peruana para la Conservación de la Naturaleza, Primera edición, 2009.

ERIKSON, P. Uma singular pluralidade: a etno-história Pano. In: Carneiro da Cunha, Manuela. História dos Índios do Brasil. São Paulo: Cia. das Letras, 1992.

- Une nébuleuse compacte: le macro-ensemble Pano, L'Homme 126-128. 1993. pp. 45-58.

La Griffe des Aïeux: marquage du corps et démarquages ethniques chez les Matis d'Amazonie. Paris: Peeters, 1996. 366 pp.

FAULHABER, P. Identidades contestadas e deslocamentos Miranha na fronteira Brasil- Colômbia. In: RCO; BAINES, Stephen G. Nacionalidade e etnicidade em fronteiras. Brasília: Editora da UnB, 2005.

FLECK, D. A Grammar of Matses. PhD Thesis. Rice University, Houston, 2003.

GALLOIS, D. T. Terras ocupadas? Territórios? Territorialidades? In: Fany Ricardo. (Org.). Terras Indígenas \& Unidades de Conservação da Natureza. São Paulo: Instituto Socioambiental, 2004. p. 37-41. 
HANNERZ, U. "Fluxos, Fronteiras, Híbridos: Palavras-Chave da Antropologia Transnacional". Mana. Estudos de Antropologia Social, 3(1):7-39, 1997.

KENSINGER, K. M. How real people ought to live. The Cashinahua of Eastern Peru. Prospect Heights: Waveland Press, 1995.

KENT, M. Práticas territoriais indígenas entre a flexibilidade e a fixação. Mana 17(3): 549-582, 2011.

KOVASNA, A. Building bodies, balancing powers - of insides, outsides and changing notions of male and female personhood among the Matses of the western Amazon. Masters Thesis, Department of Social Anthropology, Lund University, 2009.

LITTLE, P. E. Territórios sociais e povos tradicionais no Brasil: por uma Antropologia da territorialidade. Brasília: UnB, 2002. Série Antropologia $\mathrm{n}^{\circ} 322.32 \mathrm{p}$.

LÓPEZ GARCÉS, C. L. Ticunas brasileros, colombianos y peruanos: etnicidad y nacionalidad en la región de frontera del alto Amazonas/Solimões. Brasília: Ceppac, 2000 (tese de doutorado).

Procesos de formación de fronteras en la región del Alto Amazonas/Solimões: la historia de las relaciones interétnicas de los Ticuna. In: RCO; BAINES, Stephen G. Nacionalidade e etnicidade em fronteiras. Brasília: Editora da UnB, 2005.

MALDI, D. A questão da territorialidade na etnologia brasileira. Sociedade e Cultura, 1(1): 1-17, jan./jun., 1998.

MATLOCK, J. Dispersed, nucleated, dispersed: Changing Matses settlement patterns, 1969-1995. In: Picchi, D. (Ed.). Unsettled Communities: Changing Perspectives on South American Indigenous Settlements. South American Indian Studies, 5, pp.33-45, 1998.

Registers of Resistance and Accommodation: The Structuration of a Peruvian Amazonian Society. Ph.D. Dissertation in Anthropology, Southern Illinois University, Carbondale. 2002

MATOS, B. Os Matsés: aspectos históricos e contemporâneos. CTI, 2008. Manuscrito.

Disponível em: 
http://www.trabalhoindigenista.org.br/Docs/MatosBA_Os-Matsésaspectos-historicos-e-contemporaneos.pdf acesso em maio de 2011.

Os Matsés e os Outros - elementos para a etnografia de um

povo indígena do Javari/Beatriz de Almeida Matos - 2009 (Dissertação de Mestrado, MN/UFRJ).

MEDEIROS, R. A. L. "Delineando um quadro para pensar discursos geopolíticos ambientais para a Amazônia: internacionalização, nacionalismos e governanças globais no Brasil e nos EUA". Série Ceppac, n.023, 2009, 36p.

MONTAGNER, D. Projeto de Estudo para eleição de áreas indígenas na bacia do Rio Javari, 1980.

MONTAGNER, D. \& MELATTI, J. C. "Relatório sobre os índios Marúbo". Série Antropologia, n. 13, Brasília, Universidade de Brasília, 1975.

NASCIMENTO, H. Madeireiros peruanos detonam o Vale do Javari. In: RICARDO B., RICARDO F., (Eds.) Povos Indígenas no Brasil 2001/2005. São Paulo: Instituto Socioambiental. 2006a. pp. 440-442

A Terra Indígena Vale do Javari e a Fronteira Peruana. CTI, 2006b. Manuscrito. Disponível: http://www.trabalhoindigenista.org.br/Docs/NascimentoH_A-TerraInd\%C3\%ADgena-Vale-do-Javari-e-a-Fronteira-Peruana.pdf. Acesso Mar. 2013.

OCTAVIO, C. R. \& AZANHA, G. Isolados - algumas questões para reflexão. Brasília, CTI, 2009.

OLIVEIRA, J. P. “Uma etnologia dos 'índios misturados'? Situação colonial, territorialização e fluxos culturais". Mana. Estudos de Antropologia Social, 4(1): 47-77, 1998.

. "Ação indigenista e utopia milenarista. As múltiplas faces de um processo de territorialização entre os Ticuna”. In: Bruce Albert \& Alcida Rita Ramos (orgs.). Pacificando o branco. Cosmologias do contato no norte-amazônico. São Paulo: Editora UNESP, 2002. p.277309. 
PIMENTA, J. "Povos indígenas, fronteiras amazônicas e soberania nacional. Algumas reflexões a partir dos Ashaninka do Acre" Mesa Redonda: Grupos Indígenas na Amazônia SBPC - Manaus, 2009.

. "Parentes diferentes": etnicidade e nacionalidade entre os Ashaninka na fronteira Brasil-Peru. Anuário Antropológico, 2011-I, 2012: 91-119

REESINK, E. "Índio ou Caboclo: Notas sobre Identidade Étnica dos Índios no Nordeste”. Universitas. Salvador (32): 121-137, jan./abr. 1983.

RIBEIRO, D. Os índios e a civilização. Petrópolis: ed. Vozes, 1977.

ROMANOFF, S. Matsés Adaptations in the Peruvian Amazon, Ph.D. Dissertation, Columbia University, New York, 1984.

SANTOS, F. \& BARCLAY, F. (eds.). Guía Etnográfica de la Alta Amazonía, Vol. 2. Quito: FLACSO- Ecuador/IFEA, 1994.

SPRANDEL, M. A. Breve Genealogia sobre os estudos de fronteiras \& limites no Brasil. In: CARDOSO DE OLIVEIRA, Roberto; BAINES, Stephen G. Nacionalidade e etnicidade em fronteiras. Brasília: Editora da UnB, 2005.

SOUZA MARTINS, J. Fronteira. A degradação do outro nos confins do humano. São Paulo: HUCITEC, 2009.

STETSON, G. Oil Politics and Indigenous Resistance in the Peruvian Amazon: The Rhetoric of Modernity Against the Reality of Coloniality. The Journal of Environment \& Development, 21(1), 76-97, 2012.

VELHO, O. G. Frente de expansão e estrutura agrária. Rio de Janeiro: Zahar, 1972.

Capitalismo autoritário e campesinato. Rio de Janeiro: Paz e Terra, 1976.

ZÁRATE BOTÍA, C. G. Silvícolas, siringueros y agentes estatales: el surgimiento de una sociedade transfronteiriza en la Amazonia de 
Brasil, Perú y Colombia, 1880-1932. Letícia: Universidad Nacional de Colombia. Instituto Amazónico de Investigaciones (IMANI), 2008. 